\title{
Adolescent Religiosity and Psychosocial Functioning: Investigating the Roles of Religious Tradition, National-Ethnic Group, and Gender
}

\author{
Heidi E. Stolz, ${ }^{1}$ Joseph A. Olsen, ${ }^{2}$ Teri M. Henke, ${ }^{3}$ and Brian K. Barber ${ }^{1}$ \\ ${ }^{1}$ Department of Child and Family Studies, University of Tennessee, Knoxville, TN 37996, USA \\ ${ }^{2}$ College of Family, Home, and Social Sciences, Brigham Young University, Provo, UT 84602, USA \\ ${ }^{3}$ Department of Child and Family Studies, Weber State University, Ogden, UT 84408, USA \\ Correspondence should be addressed to Heidi E. Stolz; hstolz@utk.edu
}

Received 28 November 2012; Accepted 1 April 2013

Academic Editor: Priscilla K. Coleman

Copyright (C) 2013 Heidi E. Stolz et al. This is an open access article distributed under the Creative Commons Attribution License, which permits unrestricted use, distribution, and reproduction in any medium, provided the original work is properly cited.

\begin{abstract}
This study utilized data from over 9,300 youth from 11 national or within-nation ethnic groups to evaluate the relationship between youth religiosity and youth social outcomes (social initiative, antisocial behavior) and psychological outcomes (self-esteem and depression) considering the roles of religious tradition, national-ethnic group, and gender. We created national-ethnic group by religious tradition $(\mathrm{NEG} \times \mathrm{RT})$ combinations, partitioned religiosity into between-group and within-group components, and performed a series of mixed model regressions for each outcome. The levels of all four outcomes of interest differed significantly across NEG $\times$ RT groups, and these differences were attributable to national-ethnic group rather than religious tradition. Youth reports of antisocial behavior and self-esteem were predicted by between-group religiosity. Additionally, within-group religiosity predicted all four outcomes, indicating that the protective role of religiosity functions in a comparative, or relative, manner with youth who are more religious than others in their group reaping the most benefits.
\end{abstract}

\section{Introduction}

Although religious practices differ by culture, political boundary, local community, and individual, some form of religion is influential, even central, in the lives of many people across the globe $[1,2]$. Religion is an important context for development because it provides a means of socialization in areas such as moral behavior and offers emotional support to individuals from the cradle to the grave [2, $3]$. Given cognitive advances during adolescence including increased abilities to think abstractly and understand symbolism [4], it is important to study the impact of religion during this stage. Over $80 \%$ of American teens ages 13-17 have expressed the importance of faith in their daily lives and decision making processes, and approximately 90\% have been reported to have some kind of belief in God or a "cosmic life force" [5, page 41]. Religion also plays an important role for youth elsewhere in the world. For example, Lippman and Keith [6] reported that $82 \%$ of 20,000 teens and young adults from 41 countries indicated a belief in God. Additionally, there is much support for the protective role of religion in relation to various aspects of youth wellbeing including both social (cf. [7]) and psychological (cf. [8]) outcomes.

Despite the consistency of these findings, less is known about the role of broader contextual features within which youth religiosity is situated. Cultural-religious factors such as religious affiliation and nationality might directly impact youth functioning (and therefore potentially reduce the impact attributed to religiosity), or they might alter the relationship between religiosity and youth functioning. In addition to these contextual factors, it is also important to consider the potential role of gender in any investigation of religiosity given that gender has been shown to impact both religiosity (cf. [9]) and youth functioning (cf. [10]). Therefore, the purpose of the present study was to examine the role of religion (religious tradition and religiosity) in relation to various aspects of youth functioning in a large, diverse, 
multinational sample, considering variation in gender and cultural settings.

\section{Theoretical Foundations}

Various sociological and developmental theories suggest a positive role of religion in the lives of adolescents. Durkheim's [11] theory of social integration suggests that participation in a religious organization will be associated with wellbeing. Durkheim indicated that devotion to a group and participation in community rituals, such as church services and activities, would help to ameliorate a sense of anomie in the individual. In addition, his theory proposes that religion plays an important role in legitimizing and reinforcing a given society's norms, thus providing individuals with guidelines that encourage positive behaviors. Similarly, Erikson [12] postulated that youth are attracted to ideologies that answer the larger questions in life, questions that are frequently asked in adolescence. Erikson also speculated that religion provides social support and helps develop social values, functions that are likely to protect youth from alienation.

\section{Religiosity and Youth Functioning}

Much empirical research also suggests that religiosity positively impacts both youth social (externalized) outcomes and youth psychological (internalized) outcomes.

3.1. Religiosity and Youth Social Outcomes. Religiosity has generally been shown to positively predict youth prosocial behaviors (e.g., social initiative) and negatively predict youth antisocial behaviors (e.g., substance use, delinquency). With regard to prosocial behaviors, Wagener et al. [7, page 276] found that "going to programs, groups, or services" was positively related to prosocial behaviors and attitudes. Additionally, both Wagener et al. and Dowling et al. [13] reported a relationship between adolescent self-perceived religiosity and both school engagement and helping others. "Religious importance" [14, page 727] predicted positive health behaviors such as seat belt use, dietary habits, sleep patterns, and exercise among high school seniors. Additionally, research based on representative samples of adults in the US and Canada found that prayer frequency and religious reading was positively related to volunteerism [15] and civic involvement [16].

In addition to fostering prosocial behaviors, religiosity has also been shown to predict lower levels of antisocial behavior. For example, Chadwick and Top [17] reported that private religious behaviors (praying privately, reading scripture, church magazines, and books) were negatively related to delinquency in Mormon adolescents. Additionally, higher perceived importance of religion has been found to protect against antisocial behaviors such as substance use and abuse [7, 18-21], truancy and sexual activity [19], and conduct problems including harm to others [7]. Church attendance and other measures of organizational religiousness were also negatively related to risk behaviors such as smoking, alcohol use, drug use, sexual activity, delinquency, and harming others $[7,8,19,20,22]$. Overall, there is a strong support for the relationship between religiosity with positive youth social behaviors and avoidance of negative social behaviors, though much of this work was conducted with Western samples.

3.2. Religiosity and Youth Psychological Outcomes. There is also support for the idea that religiosity fosters a more positive internal state (e.g., self-esteem) and protects against negative internalized outcomes (e.g., depression) in adolescents. Religious youth, as compared to less religious youth, have reported a stronger sense of meaning and purpose in their lives [5]. Specifically, prayer was found to be a personal resource used by Dutch youth to construct meaning [23]. Prayer frequency also encouraged self-awareness [24] and contributed positively to the feeling that one's life had a sense of purpose for both churchgoing and nonchurchgoing adolescents [25]. Additionally, Good and Willoughby [8] reported that church attendance had a unique positive association with higher levels of life satisfaction. Positive associations have also been found between personal prayer and self-esteem [26] and between overall religiosity and self-esteem [27].

Religiosity also protects against negative youth psychological outcomes such as depression. For example, perceived importance of religion [19], "relational spirituality" [28, page 1021], and "meaningfulness of religion" [29, page 563] have all been linked to lower levels of youth depression. Youth participation in worship and other religious activities also (negatively) predicted depression among American youth $[19,29]$ and Canadian youth [8]. Additionally, prayer frequency has also been linked to (less) depression among adolescents in Ireland [25] and young adults from the UK [26]. Overall, there is much support for the relationship between religiosity and youth psychological well-being.

\section{The Role of Gender}

Research suggests that the level of religiosity differs by gender. Compared to males, females attend church more often [29] and engage in personal prayer more frequently [25]. Overall, young women appear to believe and practice their religion more than young men $[9,30]$. Gender has also been shown to impact three of the four youth outcomes under consideration in the present study. Compared to girls, boys have been reported to have higher levels of self-esteem [10, 31] and antisocial behavior [32, 33] but lower levels of depression $[34,35]$.

Given that (a) gender has been found to moderate the relationships between other (e.g., parental) socialization contexts and youth functioning [36] and (b) gender has been shown to be related to both youth religiosity and youth functioning, it seems reasonable to investigate whether gender serves to moderate the link between religiosity and youth functioning. Only one study was found that tested this question. Milot and Ludden [37] reported significant gender interactions for academic self-efficacy and school bonding (with religiosity being more protective for males). However, gender interactions between religious importance and attendance were not significant for the youth outcomes 
of depression, self-esteem, and substance use or school misbehavior.

\section{Placing Religiosity in Cultural-Religious Context}

Although the research reviewed above suggests stable relationships between (a) youth religiosity and both social and psychological outcomes and (b) youth gender and both religiosity and youth functioning, several researchers have called for more research on the contextual features within which the experience of adolescent religion is situated. For example, Smith [38] indicated the need for cross-national research to determine if the religious factors influencing American adolescents are unique to American culture or if they "identify more general human processes and mechanisms that transcend such cultural and religious particularities" (page 28). Regnerus [39] indicated that "the influence of individual religiosity on personal conduct may be the strongest among religious adolescents who are embedded in contexts of like-minded others" (page 409). Two potentially salient contexts-religious tradition (affiliation) and nationality (including cultural heritage and national identity) - are reviewed below.

First, although all religions follow common patterns of experience enabling adherents to share values, deepen understanding, and assist in making ethical choices, interpretations of these experiences and prescribed rules for living differ by religious tradition [1]. This diversity has the potential to differentially impact youth outcomes. Specifically, outcomes that have been shown to vary as a function of religious affiliation including alcohol use [32, 40-43], general well-being and death anxiety [44], and childhood behavioral problems [45]. It is also possible that the relationship between religiosity and youth functioning differs as a function of specific religious affiliation (i.e., a moderating effect); however, no studies were located that tested this notion. Overall, there is much support for the idea that youth functioning (especially antisocial behavior and substance use) varies by religious tradition.

Second, nation and culture of origin might also be differentially directly linked with youth functioning. Specifically, motives for engaging in alcohol use [46], risky behaviors [47], ethnic prejudice [48], cyberbullying [49], apathy [50], depressive symptoms [51], and suicidal attitudes [52] have all been reported to vary cross-nationally. In an effort to explicitly compare religious tradition effects with nationality effects, Northover and Gonzalez [53] compared Roman Catholics in Spain with Canadian Catholics and Canadian Protestants to determine if religious beliefs were influenced more by culture or religion. They hypothesized that the differences would be greater between the two cultures than between the two religious groups in Canada, and this hypothesis was confirmed.

The work of Inglehart and colleagues [54-56] provides a potential explanation for Northover and Gonzalez's [53] finding that nationality was more influential than religious tradition. Theories of secularization suggest that the influence of religion has gradually declined. However, Inglehart maintains that long established cultural patterns based on the strong influence of religion in the past are still apparent today. Specifically, Inglehart and colleagues reported that cultural differences between societies are rooted in their historical, religious, and linguistic heritage. Thus, the influence of religious tradition is less direct than that of the cultural or national group regarding many indicators of quality of life and well-being.

The present study pursues this question of the contextual, or situated, nature of religion. We consider whether "cultural (or) religious peculiarities" [38, page 28] impact the experience of religion for adolescents. We also investigate two different types of potentially "like-minded others" [39, page 409] - those who share one's geographic location and cultural heritage, and those who share one's religious faith systemto determine whether those two contexts (collectively, and if so, individually) impact youth functioning and/or the relationship between religiosity and youth functioning.

\section{Summary, Research Questions, and Hypotheses}

In sum, our investigation is responsive to the current state of knowledge in that we begin with the notions that (a) religiosity plays a generally protective function in the lives of youth, (b) gender is related to both religiosity and youth functioning, (c) nationality, ethnicity, and religious tradition, collectively (i.e., cultural-religious context), are likely to impact youth functioning, and (d) where cultural-religious effects are found, they are likely to be statistically attributable to national-ethnic group more so than to religious tradition. We advance the present state of knowledge by (a) replicating the anticipated patterns with a large, geographically-diverse sample, (b) investigating whether the salient features of religiosity operate at the within-group level (i.e., in a relative manner) or at the between group level (i.e., in a general manner), and (c) testing whether gender and culturalreligious context moderate the religiosity-youth functioning links. Specific research questions and hypotheses (where warranted) are indicated below.

(Q1) Does religiosity (i.e., between-group and withingroup religiosity) predict youth self-esteem, social initiative, depression, and antisocial behavior controlling for gender?

(H1) Higher levels of religiosity will be positively related to social initiative and self-esteem and negatively related to antisocial behavior and depression.

(Q2) Does youth gender moderate the relationships between youth religiosity and youth self-esteem, social initiative, depression, and antisocial behavior?

(H2) Gender will (directly) predict youth antisocial behavior, self-esteem, and depression. No hypothesis is advanced for the relationship between gender and social initiative or for the moderating role of gender. 
(Q3) Do levels of youth self-esteem, social initiative, depression, and antisocial behavior differ by culturalreligious context controlling for gender and religiosity?

(H3) There will be significant variability in these outcomes as a function of cultural-religious context.

(Q4) Does cultural-religious context moderate the relationships between youth religiosity and youth selfesteem, social initiative, depression, and antisocial behavior?

(Q5) Where significant variability across cultural-religious groups is observed in youth outcomes or in the relationship between religiosity and youth outcomes, is this primarily attributable to national-ethnic group or to religious tradition?

(H4) Where cultural-religious group is significant, its explanatory power will be a function of national-ethnic group more so than religious tradition.

\section{Method}

7.1. Sample and Instrument. Data for these analyses stem from the Cross-National Adolescence Project (C-NAP), a survey and interview project of over 9,300 youth from 11 national or within-nation ethnic groups (see [57], for a full description of the study). The nine general locations were selected because they represented diversity (e.g., societies in peace versus those in conflict, family size, level of economic development, religious tradition, etc.) with regard to factors that had the potential to impact family socialization experiences and personal development of school-going youth. In all cases but South Africa, the on-site collaborator selected the schools in a general effort to maximize the diversity that existed in that particular urban setting (often by selecting schools serving wealthy, moderate income, and poor students). In South Africa, where other project priorities necessitated a different sampling strategy, a stratified random sample of three ethnic groups of school-going youth in Cape Town was gathered. We thus use the term national-ethnic group (NEG) to refer to distinctive national and/or ethnic populations, seven of which are nations, one of which is contested territory (Palestine), and three of which are withinnation ethnic groups (South Africa-black, coloured, and white).

With assistance from an on-site native colleague, surveys were administered to mostly urban, school-going youth aged 14-17 in classrooms of selected schools. Table 1 presents the national-ethnic group, sample size, city where data were collected, and language of the survey.

\subsection{Measures}

7.2.1. Youth Antisocial Behavior. Eight items from the Delinquency subscale of the Child Behavior Checklist-Youth SelfReport (CBC-YSR; [58]) were used to measure youth antisocial behavior. Sample items are "I use alcohol or drugs for nonmedical purposes," "I disobey at school," and "I lie
TABLE 1: Sample size, language, and location of data collection $(N=$ 9302).

\begin{tabular}{lccc}
\hline Nation/ethnic group & Sample size & Location & Language \\
\hline Africa & & & \\
$\quad$ South Africa black & 635 & Cape Town & Xhosa \\
South Africa coloured & 520 & $\begin{array}{c}\text { Cape Town } \\
\text { Cape Town }\end{array}$ & $\begin{array}{c}\text { Afrikaans } \\
\text { English }\end{array}$ \\
$\quad$ South Africa white & 579 & & \\
Asia & & Dhaka & Bangla \\
$\quad$ Bangladesh & 1084 & Beijing & Mandarin \\
China & 1027 & Bangalore & English \\
$\quad$ India & 976 & Sarajevo & Bosnian \\
Europe & 584 & Darmstadt & German \\
$\quad$ Bosnia & 970 & Gaza Strip & Arabic \\
$\quad$ Germany & & & \\
Middle East & 978 & Ogden, UT & English \\
$\quad$ Palestine & & & \\
North America & 1001 & Bogotá & Spanish \\
$\quad$ United States & & &
\end{tabular}

or cheat." Response options ranged from $0=$ not true to $2=$ very or often true.

7.2.2. Youth Social Initiative. Social initiative, a measure of prosocial behavior, was conceptualized as the degree to which youth initiate interaction with peers and adults outside of the home. Eight items from a 13-item social initiative scale (see [59]) were used to tap social initiative in the present study. Subjects responded on a 5 -point scale from $1=$ never/almost never true to 5 = very often/always true. Items included "I share feelings and ideas with peers," "I talk to teachers and staff about things other than class," and "I help other students in need."

7.2.3. Youth Self-Esteem. Self-esteem was measured using the 10-item Rosenberg Self-Esteem scale [60]. Sample items included "I certainly feel useless at times" and "I take a positive attitude toward myself." Responses ranged from $1=$ strongly agree to $5=$ strongly disagree. Items were reversescored as necessary such that a higher value on this scale reflected a higher level of self-esteem.

7.2.4. Youth Depression. The Child Depression Inventory (CDI; [61]) was used to assess youth depression. Youth were provided 10 sets of three statements each and were asked to choose the statement within each set that most accurately described their feelings over the prior two weeks. One sample item set was "I am sad once in a while," "I am sad many times," and "I am sad all the time."

7.2.5. Religious Tradition. Religious affiliation (denomination) was measured by one item: "What is your religious preference?" Surveys conducted in each country included a list of the religions pertinent to that particular nation 
TABLE 2: Measure reliability by national-ethnic group.

\begin{tabular}{|c|c|c|c|c|c|}
\hline & Social initiative & Depression & Self-esteem & Anti-social behavior & Religiosity \\
\hline Bangladesh & .609 & .552 & .603 & .608 & .634 \\
\hline Bosnia & .762 & .755 & .814 & .804 & .800 \\
\hline China & .807 & .763 & .825 & .729 & .654 \\
\hline Colombia & .770 & .757 & .757 & .719 & .668 \\
\hline Germany & .729 & .775 & .849 & .736 & .829 \\
\hline India & .768 & .688 & 699 & .765 & .683 \\
\hline Palestine & .770 & .642 & .653 & .659 & .707 \\
\hline South Africa black & .750 & .663 & .515 & .786 & .761 \\
\hline South Africa coloured & .791 & .790 & .797 & .746 & .738 \\
\hline South Africa white & .797 & .775 & .819 & .744 & .863 \\
\hline United States & .866 & .829 & .906 & .835 & .892 \\
\hline
\end{tabular}

or ethnic group as well as the additional categories: atheist, nonreligious, no preference, and other, resulting in a total of 27 religious affiliation categories. Using criteria from the CIA World Factbook [62] and the World Council of Churches [63], these 27 options were collapsed into the following religious tradition categories: Buddhist, Hindu, Muslim, and no preference (all four of which reflected the direct responses of participants); Christian (a combination of Anglican, Catholic, Christian, Evangelical, Jehovah's Witness, Mormon (LDS), New Apostolic, Nonsectarian Christian, Pentecostal, Protestant, Protestant Free Church, Protestant National Church, Russian/Greek Orthodox, and Seventh Day Adventist); and other (those who selected denominations not listed above as well as those who selected other). These "religious tradition" categories [5, page 308] include the predominant religions in the world today based on the number of followers [1] with the exception of Judaism and Sikhism. Due to the small sample sizes, participants who selected Jewish $(n=77)$ or Sikh $(n=10)$ were merged into the category Other. Although the approach we have taken to construct the Christian category may fail to recognize important distinctions among subgroups of Christians, it is just as likely that there are important distinctions within the other broad religious tradition groups for which we do not have subgroup data. Additionally, there is support for the use of an overall Christian category (cf. $[45,64,65])$. Those who selected Atheist $(n=167)$ or non-religious $(n=147)$ as well as those who did not respond to the religious affiliation item ( $n=385)$ were excluded from further analysis because it seemed inappropriate to investigate the role of religiosity among individuals in those categories.

7.2.6. Religiosity. Two items were intended to tap organizational (public) religiousness. The first item was "How frequently do you attend religious services/traditional spiritual ceremonies?" Response options ranged from $1=$ weekly to $6=$ never but were reverse coded for ease of interpretation. The second organizational religiousness item was, "In the last 6 months, how many times have you seen or spent time with church leaders?" Responses ranged from $1=$ not at all to $7=$ every day. One additional item was intended to tap overall religious importance: "How religious do you consider yourself to be?" Responses ranged from $1=$ extremely to $5=$ not at all, but these were again reverse-scored for ease of interpretation. This one item was not asked in Colombia. Four items were designed to tap private religious practices, each on a 7point Likert scale. Responses ranged from $1=$ not at all to $7=$ every day. The items asked respondents to report how often they do each of the following: (a) "read scriptures by yourself," (b) "pray privately," (c) "think seriously about religion," and (d) "talk about religion with your friends." Given that various scholars have theorized that different aspects of religiosity are distinct constructs [39], we investigated whether the private religious practice items would factor separately from the organizational religiousness and religious importance items. However, maximum likelihood factor analysis indicated that all seven religiosity items loaded on a single factor (i.e., only one Eigen value exceeded 1.0) with factor loadings ranging from .435 to .805 . As a result, we constructed a seven-item religiosity scale by averaging scores for the seven items.

Cronbach's alpha reliability coefficients for all constructed scales within each national-ethnic group are provided in Table 2. Table 3 provides means and standard deviations for youth outcomes by religious tradition, including nonreligious youth (a combination of those who selected "Atheist" and those who selected "non-religious"). Given that the subsamples used in the present study do not generalize to national-ethnic groups (NEGs) or to religious traditions (RTs), we offer Table 3 for use in sample-specific descriptive comparisons only. Global descriptive statistics, reliability coefficients, and correlations among constructed scales are provided in Table 4 only for those included in subsequent analyses (i.e., excluding non-religious youth).

7.3. General Plan of Analysis. In general, we were interested in identifying the roles of religiosity, religious tradition, national-ethnic group, and gender in predicting four areas of youth functioning. To address our stated research questions, we created national-ethnic group $\times$ religious tradition $(\mathrm{NEG} \times \mathrm{RT})$ combinations, as evidenced by Table 5 . Each cultural-religious $(\mathrm{NEG} \times \mathrm{RT})$ group included all youth from a particular one of the 11 national-ethnic groups who was affiliated with a particular one of the 6 religious 
TABLE 3: Means and standard deviations for youth outcomes by religious tradition category.

\begin{tabular}{lllllllll}
\hline & \multicolumn{2}{c}{ Self esteem } & \multicolumn{2}{c}{ Depression } & \multicolumn{2}{c}{ Social initiative } & \multicolumn{3}{c}{ Antisocial behavior } \\
& Mean & SD & Mean & SD & Mean & SD & Mean & SD \\
\hline Buddhist & 3.604 & .613 & 1.500 & .305 & 2.980 & .736 & .361 & .334 \\
Christian & 3.757 & .684 & 1.363 & .300 & 3.379 & .794 & .423 & .368 \\
Hindu & 3.406 & .564 & 1.398 & .279 & 3.194 & .789 & .313 & .245 \\
Muslim & 3.531 & .612 & 1.462 & .287 & 3.132 & .729 & .350 & .281 \\
No preference & 3.691 & .672 & 1.449 & .330 & 3.105 & .756 & .313 & .342 \\
Other & 3.612 & .643 & 1.425 & .332 & 3.300 & .813 & .361 & .328 \\
Atheist/non religious & 3.698 & .695 & 1.477 & .331 & 3.077 & .711 & & .361 \\
\hline
\end{tabular}

TABLE 4: Correlations of constructed scales for girls (above diagonal; $n=4346$ ) and boys (below diagonal; $n=3905$ ), global means and standard deviations.

\begin{tabular}{|c|c|c|c|c|c|}
\hline Variables & $(1)$ & $(2)$ & (3) & (4) & (5) \\
\hline (1) Religiosity & - & $.05^{* *}$ & $-.07^{* *}$ & $-.18^{* *}$ & $.20^{* *}$ \\
\hline (2) Self-esteem & -.02 & - & $-.54^{* *}$ & $-.18^{* *}$ & $.29^{* *}$ \\
\hline (3) Depression & -.02 & $-.53^{* *}$ & - & $.19^{* *}$ & $-.23^{* *}$ \\
\hline (4) Antisocial behavior & $-.12^{* *}$ & $-.18^{* *}$ & $.17^{* *}$ & - & -.01 \\
\hline (5) Social initiative & $.18^{* *}$ & $.26^{* *}$ & $-.20^{* *}$ & $-.04^{*}$ & - \\
\hline Overall mean (SD) & $3.43(1.38)$ & $3.62(.65)$ & $1.42(.30)$ & $.34(.34)$ & $3.23(.78)$ \\
\hline Mean (SD) for females & $3.49(1.35)$ & $3.57(.65)$ & $1.45(.31)$ & $.30(.32)$ & $3.25(.78)$ \\
\hline Mean (SD) for males & $3.36(1.39)$ & $3.68(.65)$ & $1.38(.28)$ & $.40(.36)$ & $3.21(.77)$ \\
\hline Cronbach's alpha & .81 & .78 & .72 & .75 & .77 \\
\hline
\end{tabular}

${ }^{*} p<.01 ;{ }^{* *} p<.001$.

tradition categories. This produced 47 distinct groups of respondents across the societies sampled in the study. The members of each cultural-religious group shared a particular combination of national-ethnic group and religious tradition.

Our study used multilevel modeling, sometimes called hierarchical linear modeling or mixed model regression, to analyze data from these groups and the individuals belonging to (nested within) the groups [66]. With such data, multilevel modeling considers variables and effects at both the individual level (level one) and at the group level (level two). The main variables used in our analyses (religiosity, youth functioning outcomes, and gender) were measured initially at the individual level. After first centering the religiosity variable at its grand mean to facilitate interpretation of intercepts and interactions, we partitioned the main independent variable, religiosity, into between-group and within-group components. The between-group component consisted of the group means for religiosity, where the groups were the $\mathrm{NEG} \times \mathrm{RT}$ combinations, while the within-group component consisted of the deviations of individual respondents' scores from these group means. When used with the group mean component, the within-group component represents the relative level of religiosity compared to the group average.

We performed a series of multilevel or mixed model regressions with maximum likelihood estimation, using the mixed procedure in SPSS 16.0. Separate models were estimated for each of the four outcomes (social initiative, depression, self-esteem, and antisocial behavior). Conceptually, this approach allowed us to evaluate whether the four outcomes, or the role of religiosity in predicting them, varied as a function of the NEG $\times$ RT combinations. If such variability was found, we could then move on to investigate whether the variability was predominant due to national-ethnic group or to religious tradition.

The fixed effect estimates are interpreted as regression coefficients in other (i.e., OLS) regression models, indicating an effect of a given predictor on a designated outcome variable. Large or statistically significant variance and covariance components indicate the presence of nontrivial group variability or covariation in the associated group slopes or intercepts. Due to the large sample size, we chose to use $p<$ .01 for determining statistical significance of results.

We utilized Optimal Design software to perform a posthoc power analysis. There were 47 levels two units. The intraclass correlations for the four major outcome variables are as follows: social initiative (.041), self-esteem (.088), depression (.046), and antisocial behavior (.096). Given the number of clusters and average cluster size in our design, it is possible to detect effect sizes of .20 and .28 with $80 \%$ power at the .01 significance level, using .04 and .08 as lower and upper estimates of intra-class correlation. The magnitude of these effects is generally considered small to medium.

\section{Results}

The analysis proceeded in several steps. In the first step, initial random intercept models with fixed effects for within- and 
TABLE 5: Row-based percentages of cultural-religious $(\mathrm{NEG} \times \mathrm{RT})$ subsamples.

\begin{tabular}{|c|c|c|c|c|c|c|c|}
\hline & Buddhist & Christian & Hindu & Muslim & Other & No preference & Total \\
\hline South Africa black & $.87 \%$ & $67.07 \%$ & 0 & $1.91 \%$ & $22.70 \%$ & $7.45 \%$ & 577 \\
\hline South Africa coloured & 0 & $46.08 \%$ & 0 & $27.84 \%$ & $24.31 \%$ & $1.76 \%$ & 510 \\
\hline South Africa white & $.18 \%$ & $50.46 \%$ & 0 & $.37 \%$ & $40.70 \%$ & $8.29 \%$ & 543 \\
\hline Asia: Bangladesh & $.28 \%$ & 0 & $10.42 \%$ & $89.30 \%$ & 0 & 0 & 1084 \\
\hline Asia: China & $16.45 \%$ & $14.78 \%$ & 0 & $1.91 \%$ & $5.60 \%$ & $61.26 \%$ & 839 \\
\hline Asia: India & $.11 \%$ & $9.25 \%$ & $70.70 \%$ & $10.79 \%$ & $2.86 \%$ & $5.84 \%$ & 908 \\
\hline Europe: Bosnia & 0 & $2.80 \%$ & 0 & $.17 \%$ & $.17 \%$ & $1.05 \%$ & 573 \\
\hline Europe: Germany & $2.08 \%$ & $64.67 \%$ & $.16 \%$ & $11.43 \%$ & $4.50 \%$ & $17.21 \%$ & 866 \\
\hline Middle East: Palestine & 0 & $1.49 \%$ & 0 & $97.98 \%$ & $.53 \%$ & 0 & 940 \\
\hline South America: Columbia & 0 & $86.54 \%$ & 0 & 0 & $3.4 \%$ & $10.13 \%$ & 908 \\
\hline North America: US & 0 & $69.01 \%$ & 0 & 0 & $9.82 \%$ & $21.70 \%$ & 855 \\
\hline Total for groups & $1.98 \%$ & $35.67 \%$ & $8.79 \%$ & $32.63 \%$ & $8.24 \%$ & $12.70 \%$ & 8603 \\
\hline
\end{tabular}

between-group religiosity were estimated for each of the four dependent variables. In each case, there was a significant variance component for group membership, indicating that there was significant variation in the four youth outcomes across the NEG $\times$ RT groups. This was true for antisocial behavior $(Z=3.875, p<.001)$, depression $(Z=3.660$, $p<.001)$, self-esteem $(Z=3.648, p<.001)$, and social initiative $(Z=3.551, p<.001)$. These models therefore demonstrated that significant variation existed in the youth outcomes that could potentially be subsequently explained with the inclusion of other model predictors.

Next, in order to investigate whether gender, religiosity, or the interaction between gender and religiosity could explain this variability, we performed additional random intercept regressions. In each of these regressions the independent variables were the within- and between-group components of religiosity, gender, and the gender $\mathrm{x}$ within-group religiosity product term. None of the dependent variables showed a statistically significant gender by religiosity interaction, indicating that the relationships between within-group religiosity and the outcomes did not differ by adolescent gender.

We then estimated models without this interaction, but including a random effect for the within-group religiosity slope. This examined whether there was significant variability in the effect of religiosity on youth functioning among the NEG $\times$ RT groups which could potentially be explained by other model predictors. To summarize, the three analysis steps described above allowed us to (a) determine that there was variability to be explained in the youth outcomes across the cultural-religious $(\mathrm{NEG} \times \mathrm{RT})$ groups, $(\mathrm{b})$ determine that the effect of religiosity on the four outcomes did not vary as a function of gender, and (c) investigate whether the relationship between religiosity and youth functioning differed across cultural-religious groups. Subsequent to these steps, we will pursue the source (i.e., predominantly nationalethnic group or predominantly religious tradition) of any identified variability in the outcomes themselves, or in the relationship between religiosity and the adolescent outcomes, across the groups. The results of the third step of analysis are presented below by dependent variable.
8.1. Social Initiative. In the mixed model regression for social initiative, there was a substantial effect of the within-group religiosity component $(t=12.184, p<.001)$, indicating that individuals' deviation from their group religiosity mean predicted their level of social initiative. There was no direct effect for gender. The religiosity between-group effect was nonsignificant, suggesting that the group's mean religiosity did not predict individual social initiative (i.e., youth in groups with higher average religiosity did not have higher average social initiative). With regard to the random effects, the significant variance component for the intercepts $(Z=$ $3.535, p<.001)$ indicates that there were differences among the cultural-religious groups in the predicted levels of social initiative. Neither the variance of the slopes nor the covariance between the slopes and intercepts was statistically significant. This suggests that there was no significant variation among the slopes for the within-group component of religiosity nor was there a significant relationship between the estimated group slopes and intercepts. In other words, the effect of within-group religiosity on social initiative does not differ substantially from group to group.

8.2. Depression. The results of the mixed model regression for depression follow the same pattern as those for social initiative with the exception of gender. Results predicting depression indicate a significant effect for gender $(t=-10.772$, $p<.001$ ), with boys reporting lower levels of depression than girls. The significant effect of the within-group religiosity component $(t=-4.146, p<.001)$ indicates that individuals' deviation from their group religiosity mean predicts their depression. The between-group religiosity component was nonsignificant, meaning that the mean religiosity of the cultural-religious group did not predict individual depression. The significant intercept variation $(Z=3.590$, $p<.001)$ indicates that depression varies by group, but the nonsignificant slope variation suggests that the effect of within-group religiosity on depression does not vary by group. The covariance between slopes and intercepts was also nonsignificant. 
8.3. Self-Esteem. The results of the mixed model regression for self-esteem indicate a significant effect of the withingroup religiosity component $(t=4.106, p<.001)$, suggesting that individuals' deviation from their group religiosity mean predicts their level of self-esteem. In other words, the more religious youth are compared to counterparts within their cultural-religious group, the higher their self-esteem. The significant and substantial gender effect $(t=8.350, p<.001)$ indicates that boys reported higher levels of self-esteem than girls. The religiosity between-group effect was also significant $(t=-2.785, p<.01)$, meaning that the mean religiosity of the group predicted individual self-esteem (i.e., youth in cultural-religious groups with higher average religiosity had somewhat lower average self-esteem).

The results pertaining to the random effects were similar to those for social initiative and depression; the significant variance component for the intercepts indicated that there were differences among the cultural-religious groups in the predicted levels of self-esteem $(Z=3.612, p<.001)$. However, the nonsignificant variance component for the slopes suggests that there was no significant variation among the slopes for the within-group component of religiosity (i.e., the effect of within-group religiosity on self-esteem does not differ from group to group). The covariance between slopes and intercepts was also nonsignificant.

8.4. Antisocial Behavior. The pattern of results for antisocial behavior is distinctive in several respects. There was a significant effect for gender $(t=11.276, p<.001)$, with boys reporting higher levels of antisocial behavior than girls. Both the between-group $(t=-3.646, p<.001)$ and within-group $(t=-3.070, p<.01)$ religiosity components were significant, indicating that both the group religiosity mean, as well as individuals' deviations from it, predicted reduced antisocial behavior. The significant variance component for intercepts $(Z=3.834, p<.001)$ indicates that antisocial behavior differs by group. The significant variance component for slopes $(Z=3.278, p<.001)$ indicates that the effect of within-group religiosity on antisocial behavior differs from group to group. In addition, there was a significant negative covariance between the slopes and intercepts $(Z=-2.753$; $p<.01$ ), indicating that higher intercepts were associated with lower slopes.

8.5. National-Ethnic Group versus Religious Tradition. Given our interest in exploring the roles of religious tradition and national-ethnic group in explaining youth functioning, and the relationship between religiosity and youth functioning, we isolated the analyses suggesting differences between the NEG $\times$ RT groups and investigated whether the group differences were better understood in terms of nationalethnic group or religious tradition.

For social initiative, depression, and self-esteem, we were interested in explaining the group differences evidenced by the significant variance components for intercepts. In other words, we had identified differences in the levels of these three youth outcomes across cultural-religious groups that were constructed by jointly considering national-ethnic group (NEG) and religious tradition (RT). We now wanted to investigate whether those group differences were "driven" more by NEG or by RT, individually. To investigate the roles of NEG and RT in these group differences, we introduced, in separate models, the designated factor for NEG and for RT. In each case, we included the categorical variable as an additional fixed effect in predicting the outcome.

For antisocial behavior, we were interested in explaining the group differences evidenced in the variance components for slopes and intercepts. To evaluate the roles of NEG and RT in these group differences, we again introduced, in separate models, the designated factor for NEG and for RT. In each case, we included the categorical variable and its interaction with within-group religiosity as additional fixed effects in predicting antisocial behavior. This approach allowed us to further evaluate two findings-different levels of antisocial behavior across cultural-religious groups and different relationships between within-group religiosity and antisocial behavior across cultural-religious groups-to determine whether they were largely a function of nationalethnic group or religious tradition. Comparisons of these models with our initial baseline models for each outcome are given in Table 6.

Where possible, chi-square difference tests were conducted to test whether models introducing fixed effects for either national-ethnic group or religious tradition resulted in significant model improvement over the baseline model. In addition, the $Z$-values for the intercept variance parameters were examined to see if the variance components were reduced substantially by introducing the relevant fixed effects into the model. Adding fixed effects for religious tradition failed to improve model fit for social initiative $\chi_{\text {diff }}^{2}(5)=$ 5.496, $p=.358$, self-esteem $\chi_{\text {diff }}^{2}(5)=10.607, p=.060$, depression $\chi_{\text {diff }}^{2}(5)=7.786, p=.168$, or antisocial behavior $\chi_{\text {diff }}^{2}(10)=20.445, p=.025$. In other words, religious tradition did not explain the differences across the NEG $\times$ RT groups in any of the four youth outcomes.

Model fit was improved by adding national-ethnic group to the model for depression $\chi_{\text {diff }}^{2}(10)=46.576, p<$ .0001 , and the value of the intercept variance was no longer statistically significant $(p=.382)$. Similarly, model fit was also improved by adding national-ethnic group to the model for antisocial behavior, $\chi_{\text {diff }}^{2}(20)=104.689, p<.0001$, and the intercept and slope variances as well as the covariance between the intercepts and slopes were all nonsignificant. Adding fixed effects for national-ethnic group to the social initiative and self-esteem baseline models resulted in models which converged successfully but produced a final Hessian matrix which was not positive definite. This can sometimes happen when one or more model parameters are constrained at the boundary of their permissible parameter space. In these two models, the intercept variance estimate appears to have reached the usual boundary of zero for variance estimates during the estimation.

Strictly speaking, when this occurs, the validity of subsequent results cannot be ascertained. However, since the models converged successfully, and the reduction of the intercept variance components is consistent with the hypothesis 
TABLE 6: Comparison models for social initiative, self-esteem, depression, and antisocial behavior.

\begin{tabular}{|c|c|c|c|c|}
\hline & $-2 \mathrm{LL}$ & Parameters & AIC & $Z^{\mathrm{a}}$ \\
\hline \multicolumn{5}{|l|}{ Social initiative } \\
\hline Baseline & 18113.612 & 6 & 18125.612 & $3.543^{* *}$ \\
\hline +National-ethnic group & 18050.859 & 16 & 18082.859 & $\mathrm{~b}$ \\
\hline+ Religious tradition & 18108.166 & 11 & 18130.166 & $3.103^{*}$ \\
\hline \multicolumn{5}{|l|}{ Depression } \\
\hline Baseline & 3143.024 & 6 & 3155.024 & $3.595^{* *}$ \\
\hline +National-ethnic group & 3096.448 & 16 & 3128.448 & .874 \\
\hline+ Religious tradition & 3135.238 & 11 & 3157.238 & $3.534^{* *}$ \\
\hline \multicolumn{5}{|l|}{ Self-esteem } \\
\hline Baseline & 15385.768 & 6 & 15397.768 & $3.638^{* *}$ \\
\hline +National-ethnic group & 15313.002 & 16 & 15345.002 & b \\
\hline+ Religious tradition & 15375.161 & 11 & 15397.161 & $3.543^{* *}$ \\
\hline \multicolumn{5}{|l|}{ Antisocial behavior } \\
\hline Baseline & 4559.283 & 8 & 4575.283 & $3.834^{* *}$ \\
\hline +National-ethnic group & 4454.594 & 28 & 4510.594 & 2.088 \\
\hline +Religious tradition & 4538.838 & 18 & 4574.838 & $3.575^{* *}$ \\
\hline
\end{tabular}

of a national-ethnic group effect, we have computed the chisquare difference tests for both social initiative $\chi_{\text {diff }}^{2}(10)=$ 62.753, $p<.0001$, and self-esteem $\chi_{\text {diff }}^{2}(10)=72.766$, $p<.0001$. Recognizing the model estimation problems, we cautiously present these for comparative purposes, without trying to make strong claims as to their precision. We would additionally note that the models with fixed effects for national-ethnic group have substantially lower Akaike Information Criteria (AIC) values than either the baseline models or the models with fixed effects for religious tradition. Because the AIC is derived from the original -2 Log likelihood values, it should also be evaluated cautiously. However, taking the chi-square differences, the intercept variance component reductions, and the differential AIC values as corroborative evidence, we would conclude that the group intercept differences are substantially attributable to national-ethnic group rather than religious tradition.

\section{Discussion}

The overall purpose of the present study was to examine the role of religion (religious tradition and religiosity) in relation to various aspects of youth functioning, considering variation in gender and cultural settings. Our analytic strategy in the present manuscript was similar to a meta-analysis; we gathered illustrative samples from within each culture and drew conclusions about basic theoretical propositions pertaining to religiosity and youth functioning by assembling these samples together. The results offer both initial insights and promising directions for future research.

In support of hypothesis 2 , the results indicated direct effects of gender on three of the four youth outcomes. In keeping with the other literature (cf. $[67,68]$ ), boys reported higher levels of antisocial behavior and self-esteem but lower levels of depression than girls. We found no evidence of a gender $\times$ religiosity interaction predicting any of the four outcomes considered in the present study. Thus, on average across all cultural-religious groups, religiosity did not impact youth functioning differentially for boys and girls, but gender directly impacted youth functioning in the three stated domains. Given the breadth of the data utilized, this lack of interaction is an evidence for the common, rather than gender-specific, impact of youth religiosity.

The intercept variances were significant in predicting all four outcomes, suggesting that the levels of adolescent social initiative, depression, self-esteem, and antisocial behavior differed across cultural-religious groups, thereby supporting hypothesis 3. As expected, the unique features and experiences that are bound up in measures of religious tradition and nationality significantly impact youth outcomes at the global level. Additionally, as indicated by the slope variances, the relationship of religiosity with antisocial behavior (but not the other three outcomes) differed as a function of cultural-religious group. In other words, the protective role of religiosity on self-esteem, depression, and social initiative is similar for youth of different religious traditions and nationalities. However, cultural-religious group alters the protective function of religiosity on antisocial behavior.

Given the results that all four outcomes, as well as the relationship between religiosity and antisocial behavior, varied as a function of cultural-religious group, we endeavored to identify the primary source (i.e., national-ethnic group or religious tradition) of those differences. In keeping with hypothesis 4 and the reviewed research $[53,55]$, these differences were largely a function of national-ethnic group (NEG) rather than religious tradition (RT). Despite the fact that different religious traditions promote different specific beliefs 
and issue different behavioral expectations, those differences do not translate into varying levels of adolescent well-being. It is worth noting, though, that we can only speculate about the meaning of an NEG finding. Some NEGs have strong national identities while others have perhaps less clear identities. It could be that culture, politics, or even geography and climate play a role in these reported differences. It is also possible, as Inglehart and Baker proposed, that reported NEG differences are, in part, a function of the religious history of the regions.

Returning now to hypothesis 1 (the primary relationship between religiosity and youth functioning), all four outcomes demonstrated a "relative" effect as evidenced by the significant role of within-group religiosity. The separation of the between-group and within-group components of religiosity allowed us to investigate the contextualized effect, in other words, the effect relative to the setting in which it occurs. It appears that the relative possession of religiosity compared to other individuals in one's group is related to one's wellbeing. This is an intriguing finding, suggesting that religiosity does not function only as a "basic commodity," with each unit providing the recipient with a particular amount of protection. Rather, for all four outcomes, religiosity functions in a relative manner. The same level of religiosity might be protective in one context (where the group mean is low) but not in another (where the group mean is high), just as a given height might be an advantage on one basketball team but a disadvantage on another. Perhaps the actual protective mechanism is relative religiosity, the degree to which one is more religious than others.

In addition to the significant effect of within-group religiosity on all four outcomes, between-group religiosity significantly predicted two outcomes of interest-antisocial behavior and self-esteem. In other words, groups with higher average levels of religiosity tended to have lower levels of both antisocial behavior and self-esteem. The relationship of between-group religiosity with self-esteem was unexpected. The positive relationship of within-group religiosity with self-esteem indicates that an individual with a higher than average (for her/his group) religiosity score will have a higher predicted self-esteem score. However, the negative relationship of between-group religiosity with self-esteem indicates that an individual from a group with high average religiosity will have a lower predicted self-esteem score. This effect is similar to the so-called big-fish-little-pond effect (BFLPE) observed by Marsh et al. [69]. According to Marsh and colleagues, the BFLPE effect can be recognized when the outcome variable is positively correlated with an individuallevel predictor but negatively related to the predictor's group average. Typically, this occurs as a result of social comparison. Individuals are aware that those around them are less capable than they are in a specific area, resulting in an enhanced sense of self-concept in that area. This effect has previously been demonstrated only with domain-specific self-concept measures (e.g., academic self-concept, gymnastics self-concept), thus it is intriguing that it has perhaps been identified with religiosity predicting global self-esteem.

The results pertaining to antisocial behavior were unique and warrant additional discussion. Both the variance of slopes and covariance of slopes and intercepts were significant for antisocial behavior while not being significant for any other outcome. Thus, the effect of within-group religiosity on antisocial behavior differs from group to group, and higher levels of religiosity were generally related to weaker relationships between religiosity and antisocial behavior. It could be that in places where religiosity is somewhat uncommon, the uniqueness of it is especially protective, allowing religious youth to uniquely define themselves without having to behave antisocially in order to express nonconformity. In areas where religiosity is commonplace, youth must find another way to manifest their unique identities, and this mechanism might result in increased antisocial behavior.

This study is limited in several ways that warrant mention and consideration when interpreting or building on the findings. One methodological caution inherent for all self-report data not validated by another method (e.g., observation, other report) is shared method variance. Both the religiosity data and all outcome data were collected at the same time via the same survey. Thus, it is possible that the relationships between religiosity and measures of well-being are inflated as a result of this methodological approach. However, when the primary research question is comparative in nature (i.e., Does national-ethnic group or religious tradition better explain the differences in the youth outcomes? Is religiosity differentially related to youth well-being as a function of gender?), this shared method variance concern is less problematic because there is no reason to think that any potential correlation inflation biases the results of a comparative question. Additionally, our measurement of religiosity may be nonoptimal in one or another NEG, and we have compared religious traditions that reflect participants' direct responses (e.g., Hindu, Muslim, Buddhist) with a researcher-constructed category (Christian).

Additionally, the data are cross-sectional, so direction of effect cannot be ascertained. While there is considerably more literature suggesting that religiosity impacts well-being than vice-versa, it is still possible that some of the identified relationships involve an opposite direction of effect component as well. In all researches dealing with religion, there is the potential for socially desirable responses [2]. While this may have occurred for this study, it seems unlikely for two reasons: the frequency of reported religious behaviors is relatively low, and these data were collected as part of a much larger survey that addressed a wide variety of issues related to adolescent well-being. Lastly, while the countrybased samples were intended to capture the diversity present among school-attending youth in urban areas, we do not have random samples from these cultures. Therefore, caution should be exercised in moving from general statements about national-ethnic group and religious tradition to statements about specific NEGs or RTs.

Future cross-national research on religiosity and adolescent well-being would benefit from a richer set of religiosity items and more differentiated religious tradition categories. Given the results of the present study, future efforts should seek to identify the mechanisms that might explain these national-ethnic group differences in adolescent wellbeing and the relationship between religiosity and antisocial 
behavior. Additionally, investigations into the contingent, joint, or additive effects of family socialization and youth religiosity in predicting youth well-being may be warranted. The concept of relative religiosity also suggests a direction for future research. We hope that researchers will pursue the idea of relative religiosity to determine whether this is a conscious or a nonconscious comparison that youth make. Data such as those utilized in the present study, along with a comparative ranking measure (i.e., "How religious are you compared to your peers?"), could address this interesting question. If religious ranking relative to peers does not explain the within-group religiosity findings, then perhaps youth make this comparative assessment unconsciously.

Overall, the idea that religiosity influences youth wellbeing is well-supported in the present analyses, not just in the west but around the world. Specific religious affiliation and gender do not impact this protective mechanism, but more research is needed to better understand both (a) the mechanism linking national-ethnic group to youth wellbeing and (b) the relative, or comparative, process through which religiosity impacts all four youth outcomes.

\section{References}

[1] M. P. Fisher, Living Religions, Pearson Prentice Hall, Upper Saddle River, NJ, USA, 2005.

[2] R. W. Hood Jr., B. Spilka, B. Hunsberger, and R. Gorsuch, The Psychology of Religion: An Empirical Approach, Guilford Press, New York, NY, USA, 3rd edition, 2003.

[3] W. C. Roof, Spiritual Marketplace: Baby Boomers and the Remaking of American Religion, Princeton University Press, Princeton, NJ, USA, 1999.

[4] E. Donelson, "Psychology of religion and adolescents in the United States: past to present," Journal of Adolescence, vol. 22, no. 2, pp. 187-204, 1999.

[5] C. Smith and M. L. Denton, Soul Searching: The Religious and Spiritual Lives of American Teenagers, Oxford University Press, New York, NY, USA, 2009.

[6] L. H. Lippman and J. D. Keith, "The demographics of spirituality among youth: international perspectives," in The Handbook of Spiritual Development in Childhood and Adolescence, E. C. Roehlkepartain, P. E. King, L. Wagener, and P. L. Benson, Eds., pp. 109-123, Sage Publications, Thousand Oaks, CA, USA, 2005.

[7] L. M. Wagener, J. L. Furrow, P. E. King, N. Leffert, and P. Benson, "Religious involvement and developmental resources in youth," Review of Religious Research, vol. 44, no. 3, pp. 271-284, 2003.

[8] M. Good and T. Willoughby, "The role of spirituality versus religiosity in adolescent psychosocial adjustment," Journal of Youth and Adolescence, vol. 35, no. 1, pp. 41-55, 2006.

[9] C. Smith, M. L. Denton, R. Faris, and M. Regnerus, "Mapping American adolescent religious participation," Journal For the Scientific Study of Religion, vol. 41, no. 4, pp. 597-612, 2002.

[10] S. W. Plunkett, C. S. Henry, L. C. Robinson, A. Behnke, and P. C. Falcon, "Adolescent perceptions of parental behaviors, adolescent self-esteem, and adolescent depressed mood," Journal of Child and Family Studies, vol. 16, no. 6, pp. 760-772, 2007.

[11] E. Durkheim, The Elementary Forms of the Religious Life: A Study in Religious Sociology, Allen \& Unwin, London, UK, 1915.

[12] E. Erikson, Identity and the Life Cycle, W. W. Norton, New York, NY, USA, 1994.
[13] E. M. Dowling, S. Gestsdottir, P. M. Anderson, A. von Eye, J. Almerigi, and R. M. Lerner, "Structural relations among spirituality, religiosity, and thriving in adolescence," Applied Developmental Science, vol. 8, pp. 7-16, 2004.

[14] J. M. Wallace Jr. and T. A. Forman, "Religion's role in promoting health and reducing risk among American youth," Health Education and Behavior, vol. 25, no. 6, pp. 721-741, 1998.

[15] P.-Y. Lam, "As the flocks gather: how religion affects voluntary association participation," Journal for the Scientific Study of Religion, vol. 41, no. 3, pp. 405-422, 2002.

[16] M. T. Loveland, D. Sikkink, D. J. Myers, and B. Radcliff, "Private prayer and civic involvement," Journal for the Scientific Study of Religion, vol. 44, no. 1, pp. 1-14, 2005.

[17] B. A. Chadwick and B. L. Top, "Religiosity and delinquency among LDS adolescents," Journal for the Scientific Study of Religion, vol. 32, no. 1, pp. 51-67, 1993.

[18] National Center on Addiction Substance Abuse (NCASA), So Help Me God: Substance Abuse, Religion, and Spirituality, Columbia University, New York, NY, USA, 2001.

[19] J. W. Sinha, R. A. Cnaan, and R. J. Gelles, "Adolescent risk behaviors and religion: findings from a national study," Journal of Adolescence, vol. 30, no. 2, pp. 231-249, 2007.

[20] C. Walker, M. G. Ainette, T. A. Wills, and D. Mendoza, "Religiosity and substance use: test of an indirect-effect model in early and middle adolescence," Psychology of Addictive Behaviors, vol. 21, no. 1, pp. 84-96, 2007.

[21] T. A. Wills, A. M. Yaeger, and J. M. Sandy, "Buffering effect of religiosity for adolescent substance use," Psychology of Addictive Behaviors, vol. 17, no. 1, pp. 24-31, 2003.

[22] B. R. Johnson, S. J. Jang, S. de Li, and D. Larson, "The "invisible institution" and black youth crime: the church as an agency of local social control," Journal of Youth and Adolescence, vol. 29, no. 4, pp. 479-498, 2000.

[23] J. Janssen, J. de Hart, and C. Den Draak, "A content analysis of the praying practices of Dutch youth," Journal For the Scientific Study of Religion, vol. 29, no. 1, pp. 99-107, 1990.

[24] K. L. Ladd and B. Spilka, "Inward, outward, and upward: cognitive aspects of prayer," Journal For the Scientific Study of Religion, vol. 41, no. 3, pp. 475-484, 2002.

[25] L. J. Francis and T. E. Evans, "Insights from scholarship: the relationship between personal prayer and purpose in life among churchgoing and non-churchgoing twelve-to-fifteen-year-olds in the UK," Religious Education, vol. 91, no. 1, pp. 8-21, 1996.

[26] J. Maltby, C. A. Lewis, and L. Day, "Religious orientation and psychological well-being: the role of the frequency of personal prayer," British Journal of Health Psychology, vol. 4, no. 4, pp. 363-378, 1999.

[27] J. Ball, L. Armistead, and B. J. Austin, “The relationship between religiosity and adjustment among African-American, female, urban adolescents," Journal of Adolescence, vol. 26, no. 4, pp. 431-446, 2003.

[28] A. Desrosiers and L. Miller, "Relational spirituality and depression in adolescent girls," Journal of Clinical Psychology, vol. 63, no. 10, pp. 1021-1037, 2007.

[29] L. S. Wright, C. J. Frost, and S. J. Wisecarver, "Church attendance, meaningfulness of religion, and depressive symptomatology among adolescents," Journal of Youth and Adolescence, vol. 22, no. 5, pp. 559-568, 1993.

[30] European Commission, “The young Europeans," Eurobarometer 47. 2, 1997. 
[31] J. Lawrence, K. Ashford, and P. Dent, "Gender differences in coping strategies of undergraduate students and their impact on self-esteem and attainment," Active Learning in Higher Education, vol. 7, no. 3, pp. 273-281, 2006.

[32] W. Pedersen and A. Kolstad, "Adolescent alcohol abstainers: traditional patterns in new groups," Acta Sociologica, vol. 43, no. 3, pp. 219-233, 2000.

[33] E. E. Storvoll and L. Wichstrøm, "Gender differences in changes in and stability of conduct problems from early adolescence to early adulthood," Journal of Adolescence, vol. 26, no. 4, pp. 413429, 2003.

[34] N. L. Galambos, B. J. Leadbeater, and E. T. Barker, "Gender differences in and risk factors for depression in adolescence: a 4-year longitudinal study," International Journal of Behavioral Development, vol. 28, no. 1, pp. 16-25, 2004.

[35] A. R. MacPhee and J. J. W. Andrews, "Risk factors for depression in early adolescence," Adolescence, vol. 41, no. 163, pp. 435-466, 2006.

[36] P. Heaven and J. Ciarrochi, "Parental styles, gender and the development of hope and self-esteem," European Journal of Personality, vol. 22, no. 8, pp. 707-724, 2008.

[37] A. S. Milot and A. B. Ludden, "The effects of religion and gender on well-being, substance use, and academic engagement among rural adolescents," Youth and Society, vol. 40, no. 3, pp. 403-425, 2009.

[38] C. Smith, "Theorizing religious effects among American adolescents," Journal for the Scientific Study of Religion, vol. 42, no. 1, pp. 17-30, 2003.

[39] M. D. Regnerus, "Religion and positive adolescent outcomes: a review of research and theory," Review of Religious Research, vol. 44, no. 4, pp. 394-413, 2003.

[40] J. B. Holt, J. W. Miller, T. S. Naimi, and D. Z. Sui, "Religious affiliation and alcohol consumption in the United States," Geographical Review, vol. 96, no. 4, pp. 523-542, 2006.

[41] E. G. Karam, W. E. Maalouf, and L. A. Ghandour, "Alcohol use among university students in Lebanon: prevalence, trends and covariates: the IDRAC University Substance Use Monitoring Study (1991 and 1999)," Drug and Alcohol Dependence, vol. 76, no. 3, pp. 273-286, 2004.

[42] J. M. Oliver, C. K. S. Reed, and B. W. Smith, "Alcohol consumption and consequences in a sample of university undergraduates: patterns and relations to internalized distress and religious affiliation," North American Journal of Psychology, vol. 3, no. 1, pp. 41-61, 2001.

[43] S. Rollocks and N. Dass, "Influence of religious affiliation in alcohol use among adolescents in Trinidad, Tobago, and St. Lucia: a follow-up study," American Journal of Drug and Alcohol Abuse, vol. 33, no. 1, pp. 185-189, 2007.

[44] G. J. Morris and T. McAdie, "Are personality, well-being and death anxiety related to religious affiliation?" Mental Health, Religion and Culture, vol. 12, no. 2, pp. 115-120, 2009.

[45] M. Prior, S. Virasinghe, and D. Smart, "Behavioural problems in Sri Lankan schoolchildren: associations with socio-economic status, age, gender, academic progress, ethnicity and religion," Social Psychiatry and Psychiatric Epidemiology, vol. 40, no. 8, pp. 654-662, 2005.

[46] T. C. Link, "Youthful intoxication: a cross-cultural study of drinking among German and American adolescents," Journal of Studies on Alcohol and Drugs, vol. 69, no. 3, pp. 362-370, 2008.

[47] M. Kloep, N. Güney, F. Çok, and Ö. F. Simsek, "Motives for risk-taking in adolescence: a cross-cultural study," Journal of Adolescence, vol. 32, no. 1, pp. 135-151, 2009.
[48] R. Eisinga, J. Billiet, and A. Felling, "Christian religion and ethnic prejudice in cross-national perspective: a comparative analysis of the netherlands and flanders (Belgium)," Comparative Sociology, vol. 40, no. 3, pp. 375-393, 1999.

[49] Q. Li, "A cross-cultural comparison of adolescents' experience related to cyberbullying," Educational Research, vol. 50, no. 3, pp. 223-234, 2008.

[50] C. A. Bjornsen, J. A. Scepansky, and A. Suzuki, "Apathy and personality traits among college students: a cross-cultural comparison," College Student Journal, vol. 41, no. 3, pp. 668-675, 2007.

[51] S. M. Stewart, B. D. Kennard, C. W. Hughes et al., "A Crosscultural investigation of cognitions and depressive symptoms in adolescents," Journal of Abnormal Psychology, vol. 113, no. 2, pp. 248-257, 2004.

[52] K. Dervic, M. S. Gould, G. Lenz et al., "Youth suicide risk factors and attitudes in New York and Vienna: a cross-cultural comparison," Suicide and Life-Threatening Behavior, vol. 36, no. 5, pp. 539-552, 2006.

[53] W. E. Northover and L. M. Gonzalez, "A cross-cultural comparison of religious belief: Canadian and Spanish students'responses to the Hunt Scale," International Journal for the Psychology of Religion, vol. 3, no. 3, pp. 187-199, 1993.

[54] R. Inglehart and C. Welzel, Modernization, Cultural Change, and Democracy: The Human Development Sequence, Cambridge University Press, New York, NY, USA, 2005.

[55] R. Inglehart and W. E. Baker, "Modernization, cultural change, and the persistence of traditional values," American Sociological Review, vol. 65, no. 1, pp. 19-51, 2000.

[56] R. Inglehart and M. Carballo, "Does Latin America exist? (and is there a confucian culture?): a global analysis of cross-cultural differences," American Political Science Association, vol. 30, no. 1, pp. 34-47, 1997.

[57] B. K. Barber, H. E. Stolz, and J. A. Olsen, "Parental support, psychological control, and behavioral control: assessing relevance across time, culture, and method," Monographs of the Society For Research in Child Development, vol. 70, no. 4, pp. 1-137, 2005.

[58] T. M. Achenbach and C. S. Edelbrock, Manual For Youth Self-Report and Profile, University of Vermont, Department of Psychiatry, Burlington, VT, USA, 1987.

[59] B. K. Barber and L. D. Erickson, "Adolescent social initiative: antecedents in the ecology of social connections," Journal of Adolescent Research, vol. 16, no. 4, pp. 326-354, 2001.

[60] M. Rosenberg, Society and the Adolescent's Self-Image, Princeton University Press, Princeton, NJ, USA, 1965.

[61] M. Kovacs, Children's Depression Inventory, Multi-Health Systems, Niagara Falls, NY, USA, 1992.

[62] Central Intelligence Agency, "The World Factbook," 2012, https://www.cia.gov/library/publications/the-world-factbook/.

[63] World Council of Churches, 2012, http://www.oikoumene.org/ en/member-churches.html.

[64] F.-V. Anthony, C. A. M. Hermans, and C. Sterken, "Religious practice and religious socialization: comparative research among Christian, Muslim and Hindu students in Tamilnadu, India," Journal of Empirical Theology, vol. 20, no. 1, pp. 100-128, 2007.

[65] J. R. Knight, L. Sherritt, S. K. Harris et al., "Alcohol use and religiousness/spirituality among adolescents," Southern Medical Journal, vol. 100, no. 4, pp. 349-355, 2007.

[66] R. Bickel, Multilevel Analysis for Applied Research: It's Just Regression!, Guilford Press, New York, NY, USA, 2007. 
[67] B. J. Leadbeater, S. J. Blatt, and D. M. Quinlan, "Gender-linked vulnerabilities to depressive symptoms, stress, and problem behaviors in adolescents," Journal of Research on Adolescence, vol. 5, no. 1, pp. 1-29, 1995.

[68] M. L. Hoffmann, K. K. Powlishta, and K. J. White, "An examination of gender differences in adolescent adjustment: the effect of competence on gender role differences in symptoms of psychopathology," Sex Roles, vol. 50, no. 11-12, pp. 795-810, 2004.

[69] H. W. Marsh, K.-T. Hau, and R. G. Craven, "The big-fish-littlepond effect stands up to scrutiny," American Psychologist, vol. 59, no. 4, pp. 269-271, 2004. 

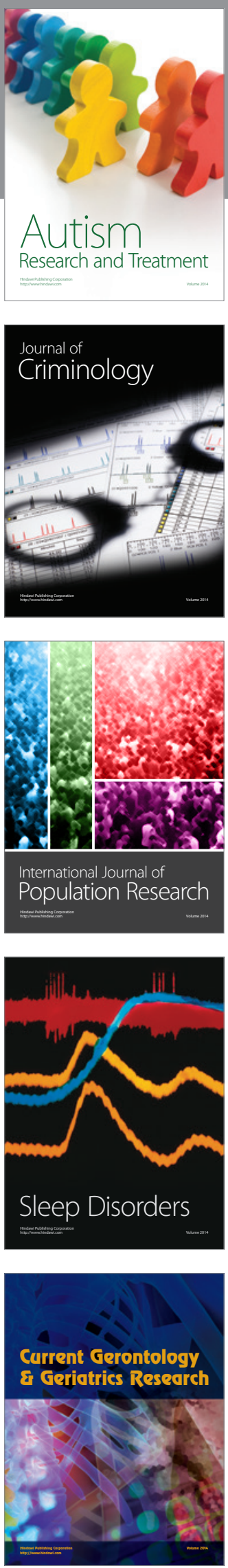
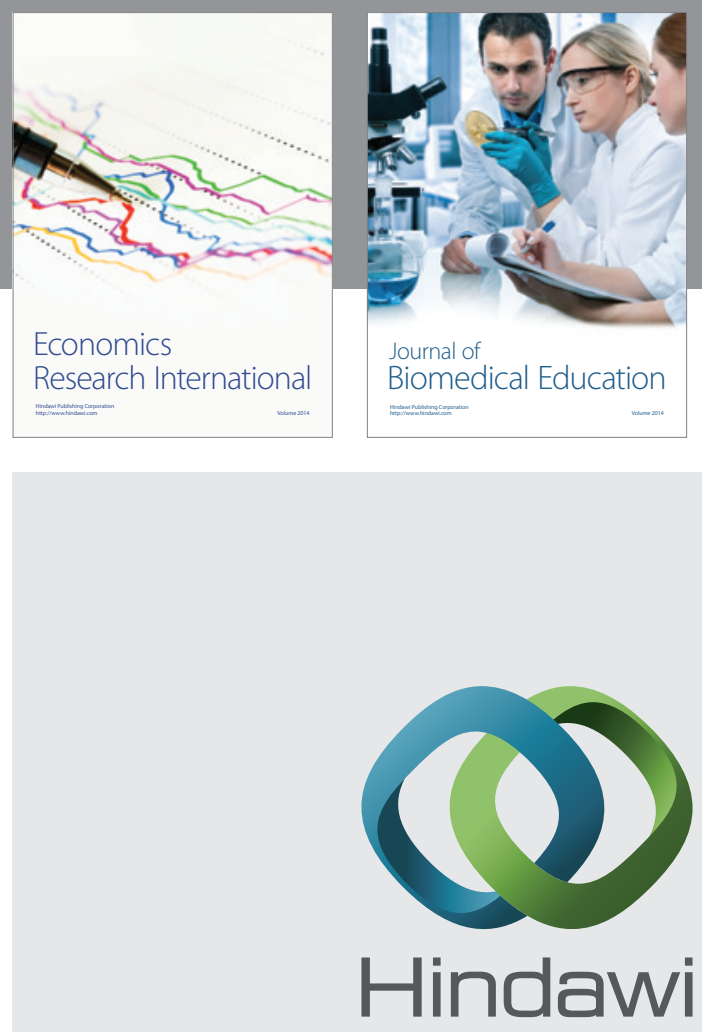

Submit your manuscripts at

http://www.hindawi.com
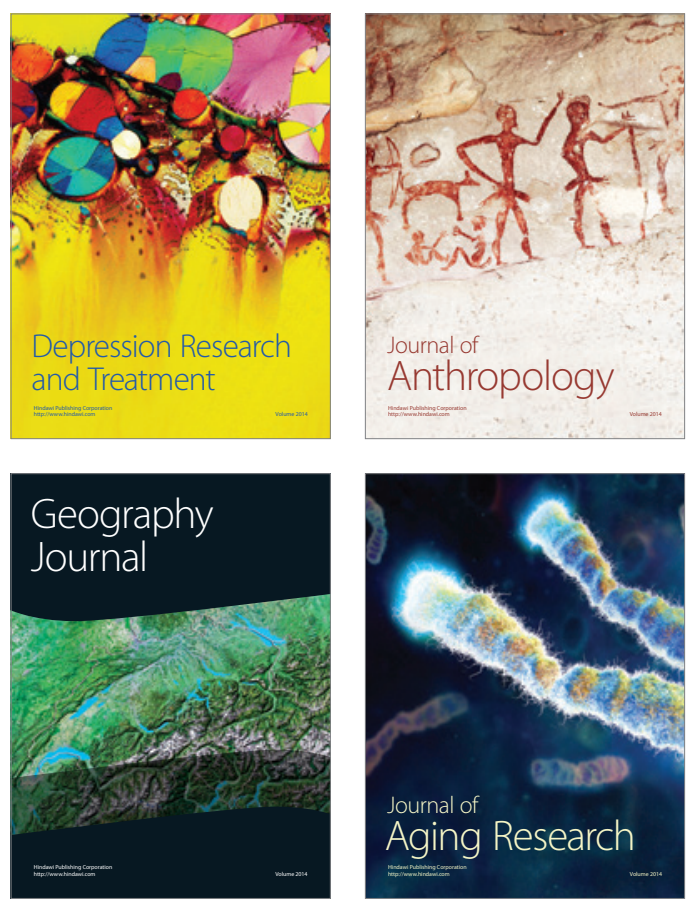
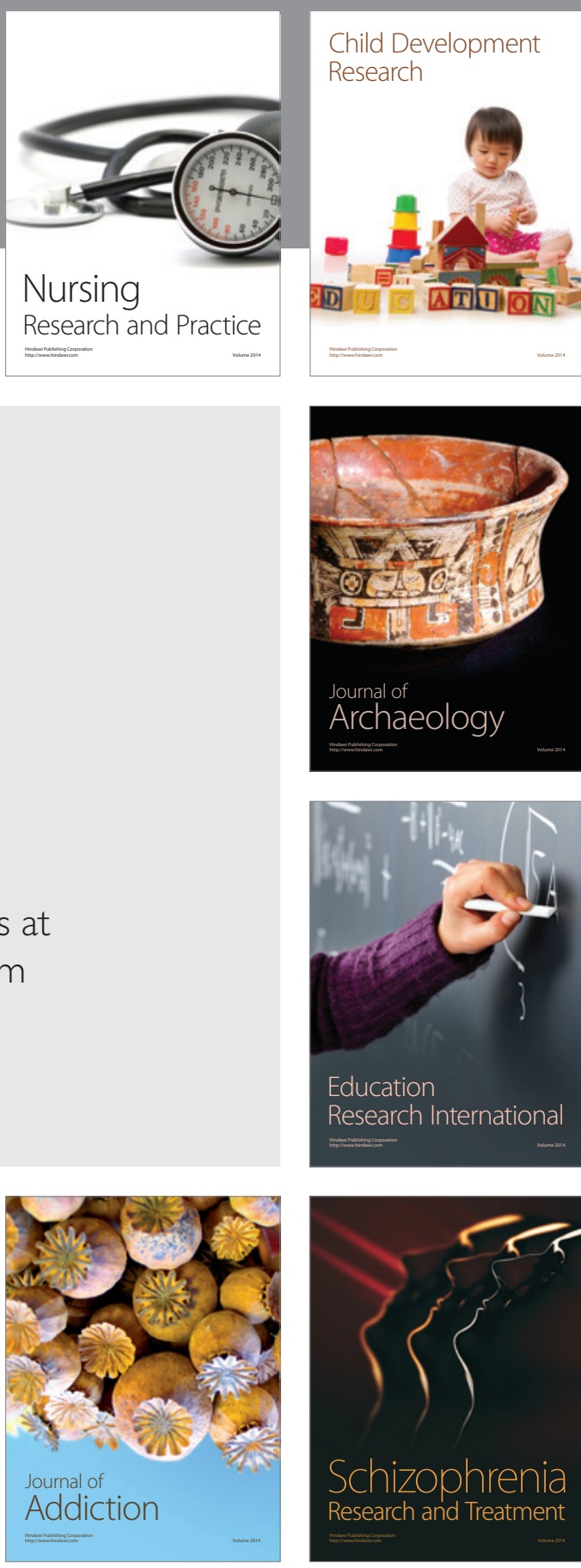

(D)
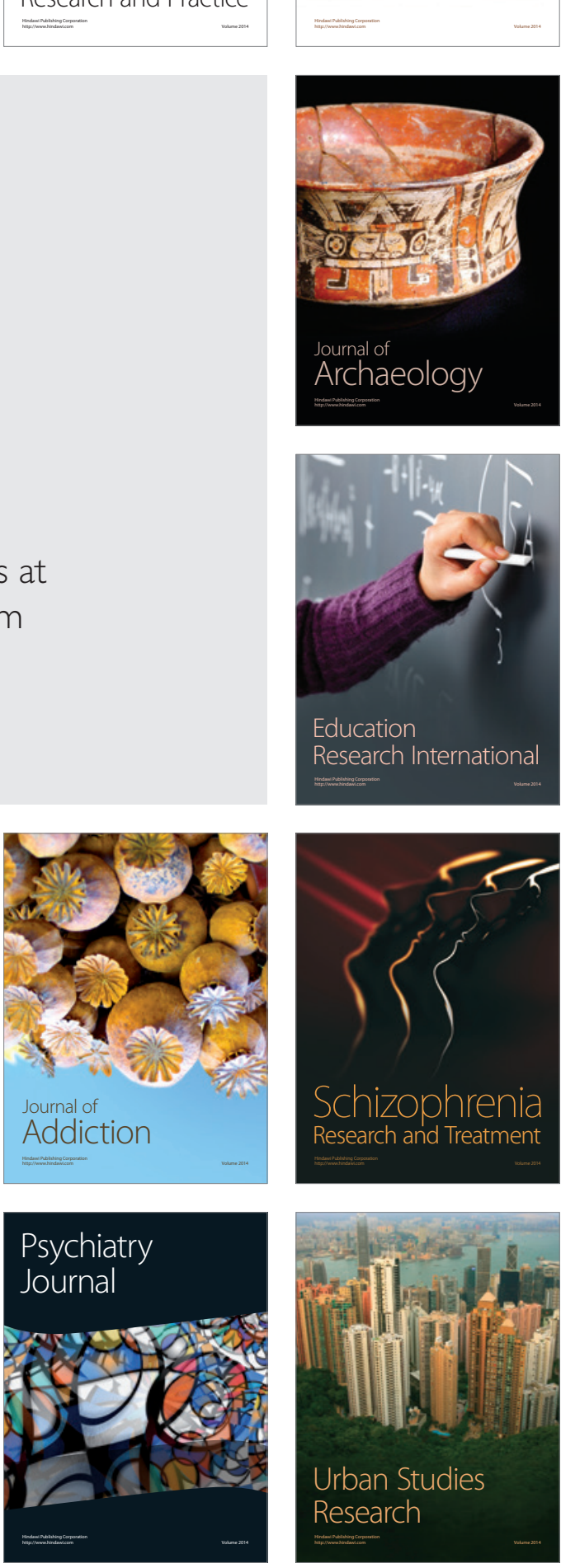